Огляди літератури, оригінальні дослідження, погляд на проблему, випадок з практики, короткі повідомлення

удК: 612.89-02:612.392.02-053.4

DOI 10.11603/1811-2471.2021.v.i2.12224

\title{
ДОСЛІДЖЕННЯ ЗМІН ПОКАЗНИКІВ ВАРІАБЕЛЬНОСТІ РИТМУ СЕРЦЯ У ДІТЕЙ З ДЕФІЦИТОМ ЙОДУ ВПРОДОВЖ НАВЧАЛЬНОГО РОКУ
}

๑О. М. Юрчишин

Тернопільський національний медичний університет імені І. Я. Горбачевського МОз України

РЕЗЮМЕ. Оцінка функціонального стану серцево-судинної системи дозволяє оцінити стан адаптації дитячого організму та спрогнозувати можливості розвитку патології, у тому числі щитоподібної залози, на донозологічному етапі, що є актуальними та необхідними для профілактики.

Мета - вивчення впродовж навчального року функціонального стану автономної нервової системи у дітей молодшого шкільного віку з йододефіцитом.

Матеріал і методи. Обстежено 239 дітей віком 6-10 років. Визначали йод в сечі та варіабельність серцевого ритму.

Результати. Встановлено, що у кінці навчального року, порівняно із початком, у дітей 1-го класу, забезпечених йодом, спостерігалося зниження показника адекватності процесів регуляції - на $11 \%(p<0,05)$, відношення індексу напруження в пробі до індексу напруження в фоновій пробі - на 38 \% (p<0,05). У дітей 2-го класу з йододефіцитом спостерігалося підвищення амплітуди моди - на 21 \% ( $<<0,05)$, показника адекватності процесів регуляції - на 26 \% ( $<<0,05)$, індексу напруження - на 56 \% ( $<<0,05)$. У четвертокласників спостерігали підвищення показників індексу напруження на $28 \%(p<0,05)$ та зниження середньоквадратичного відхилення на $37 \%(p<0,05)$.

Висновки. Встановлено, що у дітей із дефіцитом йоду переважає симпатиний вплив автономної системи. КЛЮчОВІ СЛОВА: варіабельність серцевого ритму; автономна нервова регуляція; діти; йододефіцит.

Вступ. Варіабельність серцевого ритму безпосередньо дозволяє судити про залучення тих чи інших рівнів центральної нервової системи до регуляції фізіологічних функцій, іншими словами, про рівень їх централізації, а перебіг адаптаційних процесів найкращим чином відображає функціональний стан серцево-судинної системи. Згідно з теорією Р. М. Баєвського, структура серцевого ритму дозволяє оцінити стан автономної нервової системи (вегетативний баланс), ступінь адаптаційної резистентності організму, можливості адаптаційних резервів $[1,5]$. Відомо, що чим вищий рівень центральної нервової системи, яка бере участь у регуляції функціональних систем, тим сильніше напруження адаптації $[4,11]$. Водночас доведено, що тиреоїдні гормони мають есенціальне значення для дозрівання та функціонування нервової системи. Тому дефіцит може опосередковано погіршувати перебіг адаптації через негативний вплив на диференціювання нервових клітин. Одним із найобґрунтованіших та найінформативніших методів кількісної оцінки показників вегетативної активності, параметри якої розглядають як інтегральні показники процесів регуляції організму, $\epsilon$ метод комп'ютерної кардіоінтервалографії $[3,8]$.

У зв'язку з цим для оцінки характеру впливу йододефіциту на діяльність серцево-судинної системи усім дітям проведено кардіоінтервалографію на предмет з'ясування впливу окремих відділів автономної нервової системи.

Мета - виявлення змін у показниках роботи серцево-судинної системи з використанням мето- ду варіабельності серцевого ритму в дітей молодшого шкільного віку з йододефіцитом впродовж навчального року.

Матеріал і методи досліджень. Обстежено молодших школярів з 1-го по 4-й класи на початку, у середині та у кінці навчального року. У першому класі встановлено, що 64 учні - здорові, а 29 - з йододефіцитом, у 2-му класі 34 дитини здорові, а 18 з дефіцитом йоду, у 3-му класі 33 учні з нормальним вмістом йоду, а 25 - з йододефіцитом, у 4-му класі 17 школярів здорові, а 23 з йододефіцитом. Школярі були поділені на дві групи з урахуванням йодної забезпеченості. 1-шу групу складали діти з нормальним вмістом йоду в сечі (контрольна група), 2-гу групу - з дефіцитом йоду (ДЙ) у сечі (дослідна група).

Вивчення методу варіабельності серцевого ритму здійснювали за допомогою приладу комплексної комп'ютерної діагностики «Полі-Спектр» компанії «Нейрософт». У своїй роботі ми враховували в горизонтальному (фонова проба $(\phi))$ і вертикальному (ортостатична проба (о)) положеннях такі показники: середні частоти серцевих скорочень (ЧСС), середнє арифметичне значення інтервалу R-R (M), середньоквадратичне відхилення (СК), моди (Мо), амплітуди моди (АМо), медіанне значення інтервалу R-R (Me), варіаційний розмах (BP), індекс вегетативної рівноваги (IBP), показник адекватності процесів регуляції (ПАПР), вегетативний показник ритму (ВПР), індекс напруження (IH), відношення індексу напруження в пробі до індексу напруження в фоновій пробі $\left(\mathrm{IH}_{2} / \mathrm{IH}_{1}\right)$, приріст ЧСС в ортостатичній пробі [8]. Отриманий 
Огляди літератури, оригінальні дослідження, погляд на проблему, випадок з практики, короткі повідомлення цифровий матеріал обробляли методом варіаційної статистики за Стьюдентом, а також використовували програму STATISTICA 6.0, непараметричні методи (Манна - Уїтні), P(u)=0,05, кореляційний аналіз проводили з використанням програми STATISTICA 10.0. Для визначення йодурії у дітей досліджували рівень екскреції йоду в разових порціях сечі методом Dunn I. et al. [14], пальпували щитоподібну залозу.

Результати й обговорення. При вивченні стану здоров'я дітей молодшого шкільного віку необхідно акцентувати увагу на провідній ролі визначення функціонального стану системи кровообігу, як у стані спокою, так і на фоні фізичного навантаження. При цьому слід враховувати, що поступлення до школи $є$ одним із критичних періодів у житті дитини, що супроводжується дуже високим рівнем напруження серцево-судинної та симпатоадреналової систем, а також низьким показником взаємодії різних систем між собою [12].

При визначенні у дітей молодшого шкільного віку показників йодурії у 1-му класі було виявлено 64 учні (69\%), які належним чином забезпечені йодом, та 27 школярів (29 \%) із легким ступенем дй, 1 дитина (1 \%) - із середнім ступенем тяжкості йододефіциту та 1 дитина (1 \%) - із тяжким ступенем Дй.

За показниками екскреції йоду з сечею у 2-му класі 34 дитини (65 \%) були належним чином забезпечені йодом, 14 школярів (27 \%) мали легкий ступінь тяжкості ДЙ, 4 учні (8 \%) - середній ступінь йодного дефіциту.

Серед третьокласників 33 школярі (57\%) мали нормальне йодне забезпечення та 25 учнів (43\%) мали дефіцит йоду в сечі. У 4-му класі 17 дітей (42\%) були належним чином забезпечені йодом, а 23 школярі (58 \%) мали легкий ступінь дй.

При детальному аналізі результатів варіабельності серцевого ритму встановлено, що у дітей 1-го класу з Дй на початку навчального року були менші значення показників ІВРф на $37 \%$ $(p<0,05)$, ІНф на $39 \%(p<0,05)$ щодо аналогічних даних у здорових однолітків (табл. 1), що свідчить про переважання парасимпатичного впливу АНC у школярів із йододефіцитом, що узгоджується із встановленими даними (Цяпець Г. Б., 2010). У середині навчального року в дітей із дй спостерігали менше значення величини ІНф на $36 \%(p<0,05)$, порівняно з контролем, що свідчить про переважання парасимпатичного впливу АНС у школярів дослідної групи. У кінці навчального року встановлено нижче значення ВРф на $48 \%(p<0,05)$ у школярів із ДЙ, порівняно з контрольними даними, що свідчить про домінування симпатичного впливу АНС у цих учнів. Отримані дані показали, що у першокласників на кінець навчального року спостерігали збільшення тонусу симпатичної нервової системи у дітей із дй, порівняно зі школярами з нормальним забезпеченням йодом. Виявлені зміни можна розглядати як зниження адаптаційних резервів організму, помірне виснаження регуляторних впливів, що узгоджується зі встановленими даними інших авторів $[2,4,6,11-13,16]$.

Таблиця 1. Показники варіабельності серцевого ритму у дітей 1-х класів з дефіцитом йоду (M士m)

\begin{tabular}{|c|c|c|c|c|c|c|}
\hline \multirow{3}{*}{$\begin{array}{c}\text { Фонова, } \\
\text { ортостатична }\end{array}$} & \multicolumn{6}{|c|}{ Показник } \\
\hline & \multicolumn{2}{|c|}{ початок навчального року } & \multicolumn{2}{|c|}{ середина навчального року } & \multicolumn{2}{|c|}{ кінець навчального року } \\
\hline & контроль $(n=60)$ & ДЙ $(n=27)$ & контроль $(n=60)$ & ДЙ $(n=27)$ & контроль $(n=60)$ & ДЙ $(n=27)$ \\
\hline $\mathrm{BP} \phi, \mathrm{C}$ & $1,24 \pm 0,16$ & $1,24 \pm 0,24$ & $0,72 \pm 0,09$ & $0,67 \pm 0,12$ & $1,15 \pm 0,14$ & $0,6 \pm 0,12 *$ \\
\hline IBP $\phi$, у.о. & $106,4 \pm 13,74$ & $67,43 \pm 12,97^{*}$ & $113,4 \pm 14,5$ & $79,4 \pm 15,28$ & $90,30 \pm 11,65$ & $89,7 \pm 17,26$ \\
\hline IH $\phi$, y.०. & $86,9 \pm 11,21$ & $52,98 \pm 10,19 *$ & $93,95 \pm 12,02$ & $60,5 \pm 11,64 *$ & $72,18 \pm 9,31$ & $71,8 \pm 13,82$ \\
\hline
\end{tabular}

Примітка. *-достовірність між контрольними та дослідними групами на початку, у середині та у кінці навчального року, Р<0,05.

У школярів 2-го класу з дй на початку навчального року встановлено нижчі величини ІВРф (на $44 \%$, р<0,05), ІНф (на $45 \%$, р<0,05) (табл. 2), порівняно зі здоровими однолітками, що свідчить про переважання впливу парасимпатичного відділу АНС у цих дітей. У середині навчального року в школярів із ДЙ спостерігаються вірогідно вищі значення ВРо (майже у два рази), що свідчить про переважання впливу парасимпатичної нервової системи. Зниження показника $\mathrm{IH}_{2} / \mathrm{IH}_{1}$ на $50 \%(\mathrm{p}<0,05)$ свідчить про наявність певного симпатичного тонусу у дітей з дй. Проте, виходячи із кількісного співвідношення між показниками, отриманими при аналізі серцевого ритму у дітей 2-го класу з дй у середині навчального року, парасимпатична нервова система переважає над симпатичною. У кінці навчального року нижчі значення показників Меф (на $60 \%$, р<0,05), Мео (на $72 \%$, р<0,05) та $\mathrm{IH}_{2} / \mathrm{IH}_{1}$ (на $68 \%$, p<0,05) щодо аналогічних показників у контрольній групі (табл. 2) свідчать про переважання симпатичного тонусу в учнів із ДЙ. Отримані результати показали, що в учнів других класів із дй до кінця навчального року спостерігається зростання тонусу симпатичної нервової системи [7, 9, 10, 15].

У 3-му класі (табл. 3) на початку та у середині навчального року в учнів із дй не виявлено достовірних відмінностей між даними показників 
Огляди літератури, оригінальні дослідження, погляд на проблему, випадок з практики, короткі повідомлення Таблиця 2. Показники варіабельності серцевого ритму у дітей 2-их класів з дефіцитом йоду (M士m)

\begin{tabular}{|c|c|c|c|c|c|c|}
\hline \multirow{3}{*}{$\begin{array}{c}\text { Фонова, } \\
\text { ортостатична }\end{array}$} & \multicolumn{6}{|c|}{ Показник } \\
\hline & \multicolumn{2}{|c|}{ початок навчального року } & \multicolumn{2}{|c|}{ середина навчального року } & \multicolumn{2}{|c|}{ кінець навчального року } \\
\hline & контроль $(n=34)$ & ДЙ $(n=18)$ & контроль $(n=34)$ & ДЙ $(n=18)$ & контроль (n=34) & ДЙ $(n=18)$ \\
\hline Меф, c & $0,69 \pm 0,11$ & $0,71 \pm 0,16$ & $0,67 \pm 0,11$ & $0,68 \pm 0,16$ & $1,64 \pm 0,28$ & $0,66 \pm 0,15^{*}$ \\
\hline Meo, c & $0,59 \pm 0,10$ & $0,60 \pm 0,14$ & $0,57 \pm 0,09$ & $0,59 \pm 0,14$ & $2,05 \pm 0,35$ & $0,58 \pm 0,13^{*}$ \\
\hline BPo, c & $0,88 \pm 0,15$ & $1,32 \pm 0,31$ & $1,23 \pm 0,21$ & $2,38 \pm 0,56^{*}$ & $0,90 \pm 0,15$ & $1,29 \pm 0,30$ \\
\hline IBP $\phi$, у.о. & $131,6 \pm 22,57$ & $74,0 \pm 17,34^{*}$ & $94,59 \pm 16,22$ & $96,6 \pm 22,77$ & $95,36 \pm 16,35$ & $148,8 \pm 35,08$ \\
\hline $\mathrm{IH} \phi$, y.o. & $103,3 \pm 17,72$ & $56,3 \pm 13,27 *$ & $74,16 \pm 12,71$ & $78,4 \pm 18,48$ & $74,35 \pm 12,75$ & $127,1 \pm 29,95$ \\
\hline $\mathrm{IH} 2 / \mathrm{IH} 1$ & $1,94 \pm 0,33$ & $1,90 \pm 0,44$ & $2,04 \pm 0,35$ & $1,01 \pm 0,23^{*}$ & $4,37 \pm 0,75$ & $1,42 \pm 0,33^{*}$ \\
\hline
\end{tabular}

Примітка. *-достовірність між контрольними та дослідними групами на початку, у середині та у кінці навчального року, Р<0,05.

Таблиця 3. Показники варіабельності серцевого ритму у дітей 3-х класів із дефіцитом йоду (M士m)

\begin{tabular}{|c|c|c|c|c|c|c|}
\hline \multirow{3}{*}{$\begin{array}{c}\text { Фонова, } \\
\text { ортостатична }\end{array}$} & \multicolumn{6}{|c|}{ Показник } \\
\hline & \multicolumn{2}{|c|}{ початок року } & \multicolumn{2}{|c|}{ середина року } & \multicolumn{2}{|c|}{ кінець року } \\
\hline & контроль (n=33) & ДЙ (n=25) & контроль $(n=33)$ & ДЙ $(n=24)$ & контроль (n=32) & ДЙ (n=25) \\
\hline Moф, c & $0,74 \pm 0,12$ & $0,71 \pm 0,14$ & $0,70 \pm 0,12$ & $0,69 \pm 0,14$ & $0,71 \pm 0,12$ & $0,67 \pm 0,13 *$ \\
\hline Мeф, c & $0,74 \pm 0,12$ & $0,75 \pm 0,14$ & $0,72 \pm 0,12$ & $0,71 \pm 0,14$ & $0,72 \pm 0,12$ & $0,70 \pm 0,14^{a}$ \\
\hline Meo,c & $0,61 \pm 0,10$ & $0,62 \pm 0,12$ & $0,59 \pm 0,10$ & $0,60 \pm 0,12$ & $0,62 \pm 0,10^{1}$ & $0,61 \pm 0,12$ \\
\hline $\mathrm{BP} \phi, \mathrm{c}$ & $0,61 \pm 0,10$ & $0,82 \pm 0,16$ & $0,63 \pm 0,10$ & $0,62 \pm 0,12$ & $0,53 \pm 0,09$ & $0,52 \pm 0,10$ \\
\hline BPo, C & $0,73 \pm 0,12$ & $1,01 \pm 0,20$ & $0,85 \pm 0,14$ & $1,07 \pm 0,21$ & $0,75 \pm 0,13$ & $0,84 \pm 0,16$ \\
\hline IBP $\phi, y .0$ & $82,15 \pm 14,30$ & $83,3 \pm 16,7$ & $103,44 \pm 18,0$ & $96,6 \pm 19,7$ & $92,91 \pm 16,42$ & $96,50 \pm 19,30$ \\
\hline IBPo,y.o & $92,52 \pm 16,10$ & $102 \pm 20,3$ & $97,05 \pm 16,89$ & $108,1 \pm 22$ & $84,67 \pm 14,96$ & $118,8 \pm 23,77$ \\
\hline $\mathrm{IH} \phi, y .0$ & $58,66 \pm 10,21$ & $62,7 \pm 12,5$ & $83,64 \pm 14,56$ & $73,2 \pm 14,9$ & $68,14 \pm 12,04$ & $77,12 \pm 15,42$ \\
\hline IHo, y.o & $83,75 \pm 14,58$ & $89,1 \pm 17,8$ & $86,16 \pm 14,99$ & $98,3 \pm 20,1$ & $71,29 \pm 12,60$ & $106,9 \pm 21,39$ \\
\hline $\mathrm{IH} 2 / \mathrm{IH} 1$ & $1,52 \pm 0,26$ & $1,90 \pm 0,38$ & $1,76 \pm 0,30$ & $1,47 \pm 0,30$ & $1,41 \pm 0,24$ & $1,52 \pm 0,30$ \\
\hline
\end{tabular}

варіабельності серцевого ритму, що вивчались. У кінці навчального року зниження показника Моф може свідчити про активацію впливу симпатичного відділу АНС в учнів із дй.
Водночас між показниками варіабельності серцевого ритму у школярів 4-их класів із різним йодним забезпеченням впродовж навчального року достовірних відмінностей виявлено не було (табл. 4).

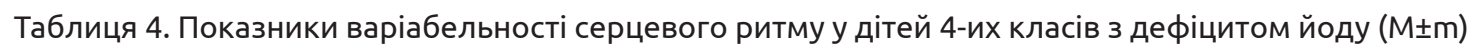

\begin{tabular}{|c|c|c|c|c|c|c|}
\hline \multirow{3}{*}{$\begin{array}{c}\text { Фонова, } \\
\text { ортостатична }\end{array}$} & \multicolumn{6}{|c|}{ Показник } \\
\hline & \multicolumn{2}{|c|}{ початок року } & \multicolumn{2}{|c|}{ середина року } & \multicolumn{2}{|c|}{ кінець року } \\
\hline & контроль $(\mathrm{n}=16)$ & ДЙ $(n=23)$ & контроль $(\mathrm{n}=17)$ & ДЙ $(n=23)$ & контроль $(\mathrm{n}=17)$ & ДЙ $(n=23)$ \\
\hline Moф, c & $0,72 \pm 0,18$ & $0,72 \pm 0,15$ & $0,74 \pm 0,18$ & $0,73 \pm 0,15$ & $0,73 \pm 0,15$ & $0,73 \pm 0,15$ \\
\hline Moo, c & $0,59 \pm 0,14$ & $0,60 \pm 0,12$ & $0,58 \pm 0,14$ & $0,62 \pm 0,13$ & $0,59 \pm 0,14$ & $0,60 \pm 0,12$ \\
\hline Мeф, c & $0,75 \pm 0,18$ & $0,71 \pm 0,14$ & $0,74 \pm 0,18$ & $0,72 \pm 0,15$ & $0,73 \pm 0,17$ & $0,74 \pm 0,15$ \\
\hline Meo,c & $0,60 \pm 0,15$ & $0,61 \pm 0,12$ & $0,59 \pm 0,14$ & $0,62 \pm 0,13$ & $0,59 \pm 0,14$ & $0,60 \pm 0,12$ \\
\hline IBP $\phi, y .0$ & $111,33 \pm 27,8$ & $161,3 \pm 33,6$ & $103,7 \pm 25,15$ & $118,23 \pm 24,6$ & $109,4 \pm 26,54$ & $107 \pm 22,4$ \\
\hline IBPo,y.o & $79,31 \pm 19,82$ & $116,0 \pm 24,2$ & $87,09 \pm 21,12$ & $89,27 \pm 18,6$ & $76,50 \pm 18,55$ & $123 \pm 25,6$ \\
\hline $\mathrm{IH} \phi, y .0$ & $78,02 \pm 19,50$ & $121,0 \pm 25,2$ & $71,96 \pm 17,45$ & $89,07 \pm 18,6$ & $77,35 \pm 18,76$ & $76,4 \pm 15,9$ \\
\hline $\mathrm{IHo}, \mathrm{y.o}$ & $69,54 \pm 17,38$ & $102,7 \pm 21,4$ & $75,75 \pm 18,37$ & $75,96 \pm 15,8$ & $66,74 \pm 16,18$ & $106 \pm 22,22$ \\
\hline $\mathrm{IH} 2 / \mathrm{IH} 1$ & $1,13 \pm 0,28$ & $1,64 \pm 0,34$ & $1,37 \pm 0,33$ & $1,37 \pm 0,33$ & $1,45 \pm 0,35$ & $2,44 \pm 0,50$ \\
\hline
\end{tabular}

Висновки. При детальному вивченні показників варіабельності серцевого ритму у дітей 1-4 класів із дефіцитом йоду впродовж навчального року домінує вплив симпатичної нервової системи (зниження показників варіаційного роз- маху на $52 \%(p<0,05)$ та збільшення індексу напруження у 2,3 раза ( $p<0,05)$, тоді як у школярів, належним чином забезпечених йодом, переважає парасимпатична нервова система (збільшення показників медіанного значення інтервалу R-R 
Огляди літератури, оригінальні дослідження, погляд на проблему, випадок з практики, короткі повідомлення у фоновій пробі у 2,4 раза $(p<0,05)$ та у ортостатичній пробі у 3,5 раза ( $p<0,05)$, відношення індексу напруження в пробі до індексу напруження в фоновій пробі у 2,3 раза ( $<<0,05)$.

Перспективи подальших досліджень. Оцінка функціонального стану серцево-судинної системи дозволяє оцінити стан адаптації дитячого

організму та спрогнозувати можливості розвитку патології, у тому числі щитоподібної залози, на донозологічному етапі. Діти, в яких за допомогою скринінг-тесту виявлена йодна недостатність, потребують поглибленого клінічного і лабораторно-інструментального обстеження не тільки щитоподібної залози, а й інших органів.

\section{ЛІТЕРАТУРА}

1. Бабій І. Л. Адаптаційні можливості школярів / І. Л. Бабій, В. І. Величко, Я. І. Венгер // Здоровье ребенка. - 2011. - № 8 (35). - С. 20-24.

2. Басанець Л.М. Вплив мікросоціального середовища на фізичний розвиток і стан здоров'я дітей та підлітків / Л. М. Басанець, О. І. Іванова // Довкілля і здоров'я. - 2010. - № 1. - С. 52-55.

3. Бережний В. В. Застосування визначення варіабельності серцевого ритму у дітей / В. В. Бережний, І. В. Романкевич // Современная педиатрия - 2015. T. 1 (65). - С. 87-90.

4. Глазков $€$. О. Показники центральної гемодинаміки при порушенні адаптації студентів молодших курсів до навчальної діяльності / Є. О. Глазков // Український журнал екстремальної медицини імені Г. О. Можаєва. - 2012. - Т. 13 (3). - С. 18-21.

5. Адаптаційно-резервні можливості організму дітей, хворих на бронхіальну астму / В. П. Костроміна, О. О. Речкіна, Л. Б. Ярощук [та ін.] // Астма та алергія. 2014. - № 3. - С. 13-19.

6. Оцінка функціональних резервів серцево-судинної системи студентів-першокурсників залежно від вмісту йоду та свинцю в організмі / А. В. Магльований, Б. А. Пластунов, М. О. Ковалів [та ін.] // Acta medika leopoliensia : Львівський медичний часопис. - 2012. № 2, T. 18. - С. 91-95.

7. Маменко М. Є. Йодний дефіцит та йододефіцитні захворювання (лекція) / М. Є. Маменко // Перинатологія і педіатрія - 2013. - № 1 (53). - С. 97-105.

8. Михайлов В. М. Вариабельность ритма сердца. Опыт практического применения метода / В. М. Михайлов. - Иваново, 2008. - 200 с.

9. Рябуха О.І. Деякі аспекти впливу щитоподібної залози на стан організму в умовах норми і патології /
О. І. Рябуха // Актуальні проблеми сучасної медицини: Вісник Української медичної стоматологічної академії. - 2018. - Т. 18, Вип. 3 (63). - С. 324-330.

10. Рябуха О. І. До структурних та функціональних передумов виникнення тиреоїдної патології (огляд літератури) / О. І. Рябуха // Здобутки клінічної і експериментальної медицини. - 2018. - № 2. - С. 16-24.

11. Оцінка адаптаційних можливостей школярів міста Києва з йододефіцитом / О. А. Строй, Л. В. Сліпачук, Л. М. Казакова, Ю. П. Резніков // Здобутки клінічної і експериментальної медицини. - 2016. - № 3. - С. 92-95.

12. Цяпець Г. Б. Роль автономної нервової системи у адаптації до навчального процесу одно- та двомовних дітей молодшого шкільного віку : автореф. дис. на здобуття наук. ступ. канд. біол. наук : 03.00.13 "Фізіологія людини і тварини" / Г. Б. Цяпець. - Львів, 2010. - 8 с.

13. Voronych S. M. Physiological Aspects of Analysis of Heart Rate Variability Parameters in Adolescents with Latent Hypothyroidism / S. M. Voronych, B. M. Pavlykivs'ka, N. M. Voronych-Semchenko // International Journal of Physiology and Pathophysiology. - 2012. - No. 3 (1). P. 151-331.

14. Dunn J. Two simple metods for measuring iodine in urine / J. Dunn, H. Grutchfield, R. Gutekunst // Thyroid. 1993. - Vol. 3 - P. 119-123.

15. Ryabukha O. I. Application of mathematical approaches in medicine on the example of follicular thyrocytes secretory activity study. World of Medicine and Biology. - 2019. - No. 1 (67). - P. 181-187.

16. Cardiovascular system indicators in the primary school aged children during the adaptation to educational loads in the region with iodine deficiency / O. M. Yurchyshyn O. S. Komissarova, T. V. Fartushok [et al.] // World of Medicine and Biology. - 2020. - No. 1 (71). - P. 149-153.

\section{REFERENCES}

1. Babii, I.L., Velychko, V.I., \& Venher, Y.I. (2011). Adaptatsiini mozhlyvosti shkoliariv [Adaptive capabilities of students]. Zdorovie Rebionka - Child Health, 8 (35), 2024 [in Russian].

2. Basanets, L.M., \& Ivanova, O.I. (2010). Vplyv mikrosotsialnoho seredovyshcha na fizychnyi rozvytok i stan zdorovia ditei ta pidlitkiv [The impact of the microsocial environment on the physical development and health of children and adolescents]. Dovkillia i zdorovia - Environment and Health, 1, 52-55 [in Ukrainian].

3. Berezhnyi, V.V., \& Romankevych, I.V. (2015). Zastosuvannia vyznachennia variabelnosti sertsevoho rytmu u

ditei [Application of determination of heart rate variability in children]. Sovriemiennaia piediatriia-Modern Pediatrics, 1(65), 87-90 [in Russian].

4. Hlazkov, Ye.O. (2012). Pokaznyky tsentralnoi hemodynamiky pry porushenni adaptatsii studentiv molodshykh kursiv do navchalnoi diialnosti [Indicators of central hemodynamics in violation of the adaptation of junior students to educational activities]. Ukrainskyi zhurnal ekstremalnoi medytsyny imeni H.O. Mozhaieva - H. Mozhaiev Ukrainian Journal of Extreme Medecine, 13(3), 18-21 [in Ukrainian].

5. Kostromina, V.P., Rechkina, O.O., \& Yaroshchuk, L.B. (2014). Adaptatsiino-rezervni mozhlyvosti orha- 
Огляди літератури, оригінальні дослідження, погляд на проблему, випадок з практики, короткі повідомлення nizmu ditei khvorykh na bronkhialnu astmu [Adaptation-reserve capabilities of the body of children with asthma] Astma ta alerhiia - Astma and Allergy, 3, 13-19 [in Ukrainian].

6. Mahlovanyi, A.V., Plastunov, B.A., \& Kovaliv, M.O. (2012). Otsinka funktsionalnykh rezerviv sertsevo-sudynnoi systemy studentiv-pershokursnykiv zalezhno vid vmistu yodu ta svyntsiu v orhanizmi [Assessment of functional reserves of the cardiovascular system of first-year students depending on the content of iodine and lead in the body]. Lvivskyi medychnyi chasopys - Lviv Medical Journal, 18 (2), 91-95 [in Ukranian].

7. Mamenko, M.Ye. (2013). Yodnyi defitsyt ta yododefi-tsytni zakhvoriuvannia (lektsiia) [lodine deficiency and iodine deficiency disorders - A lecture notes]. Perinatologiya i pediatriya - Perinatology and Pediatrics, 1 (53), 97-105 [in Ukrainian].

8. Mykhailov, V.M. (2008). Varyabelnost rytma serdtsa. Opyt praktycheskoho prymenenyia metoda. [Heart rate variability. Experience in practical application of the method]. Ivanovo [in Russian].

9. Riabukha, O.I. (2018). Deiaki aspekty vplyvu shchytopodibnoi zalozy na stan orhanizmu $v$ umovakh normy $i$ patolohii [Some aspects of the impact of the thyroid gland on the state of the body in normal and pathological conditions]. Aktualni problemy suchasnoi medytsyny: Visnyk ukrainskoi medychnoi stomatolohichnoi akademii - Actual Problems of Modern Medicine: Bulletin of the Ukrainian Medical Dental Academy, 18 (3), 324-330 [in Ukrainian].

10. Riabukha, O.I. (2018). Do strukturnykh ta funktsionalnykh peredumov vynyknennia tyreoidnoi patolohii (ohliad literatury) [To the structural and functional preconditions for the occurrence of thyroid pathology]. Zdobutky klinichnoi i eksperymentalnoi medytsyny - Achievements of Clinical and Experimental Medicine, 2, 16-24 [in Ukrainian].

11. Stroi, O.A., Slipachuk, L.V., Kazakova, L.M., \& Reznikov, Yu.P. (2016). Otsinka adaptatsiinykh mozhlyvostei shkoliariv mista Kyieva z yododefitsytom [Assessment of adaptation abilities of schoolchildren of the city of Kyiv with iodine deficiency]. Zdobutky klinichnoi i eksperymentalnoi medytsyny - Achievements of Clinical and Experimental Medicine, 3, 92-95 [in Ukrainian].

12. Tsiapets, H.B. (2010) Rol avtonomnoi nervovoi systemy u adaptatsii do navchalnoho protsesu odno-ta dvomovnykh ditei molodshoho shkilnoho viku: avtoref. dys. na zdobuttia nauk. stup. kand. biol. nauk: "Fiziolohia liudyny I tvary$n y "$ "The role of the autonomic nervous system in the adaptation to the educational process of monolingual and bilingual children of primary school age: abstract of the dissertation for the degree of Candidate of Biological Science: "Physiology of man and animal"] Lviv [in Ukrainian].

13. Voronych, S.M., Pavlykivska, B.M., \& Voronych-Semchenko, N.M. (2012). Physiological Aspects of Analysis of Heart Rate Variability Parameters in Adolescents with Latent Hypothyroidism. International Journal of Physiology and Pathophysiology, 3 (1), 151-331.

14. Dunn, J., Grutchfield, H.,. \& Gutekunst, R. (1993). Two simple metods for measuring iodine in urine. Thyroid, 3, 119-123.

15. Ryabukha, O.I. (2019). Application of mathematical approaches in medicine on the example of follicular thyrocytes secretory activity study. World of Medicine and Biology, 1 (67), 181-187.

16. Yurchyshyn, O.M., Komissarova, O.S., Fartushok, T.V., Palytsia, L.M., \& Lokai, B.A. (2020). Cardiovascular system indicators in the primary school aged children during the adaptation to educational loads in the region with iodine deficiency. World of Medicine and Biology, 1 (71), 149-153.

\section{ИССЛЕДОВАНИЕ ИЗМЕНЕНИЙ ПОКАЗАТЕЛЕЙ ВАРИАБЕЛЬНОСТИ СЕРДЕЧНОГО РИТМА У ДЕТЕЙ С ДЕФИЦИТОМ ЙОДА В ТЕЧЕНИЕ УЧЕБНОГО ГОДА}

๑О. М. Юрчишин

\section{Тернопольский национальный медицинский университет имени И. Я. Горбачевского МОЗ Украины}

РЕЗЮМЕ. Оценка функционального состояния сердечно-сосудистой системы позволяет оценить состояние адаптации детского организма и прогнозировать возможности развития патологии, в том числе щитовидной железы, на донозологическом этапе, что является актуальным и необходимым для профилактики.

Цель - изучение в течение учебного года функционального состояния автономной нервной системы у детей младшего школьного возраста с йододефицитом.

Материал и методы. Обследовано 243 детей в возрасте 6-10 лет. Определяли йод в моче и вариабельность сердечного ритма.

Результаты. В конце учебного года, по сравнению с его началом, у детей 1-го класса, обеспеченных йодом, наблюдалось снижение показателя адекватности процессов регуляции на $11 \%(p<0,05)$, отношение индекса напряжения в пробе с индексом напряжения в фоновой пробе на 38 \% ( p <0,05). У детей 2-го класса с йододефицитом наблюдалось повышение амплитуды моды на $21 \%$ ( $<<0,05)$, показателя адекватности процессов регуляции на $26 \%$ ( $<<0,05)$, индекса напряжения - на $56 \%$ ( $<<0,05)$. У четвероклассников наблюдалось повышение показателей индекса напряжения на 28 \% $(p<0,05)$ и снижение среднего отклонения на 37 \% ( $<<0,05)$. Установлено, что у детей с дефицитом йода преобладает симпатическое влияние автономной системы.

КЛЮчЕВЫЕ СЛОВА: вариабельность сердечного ритма, автономная нервная регуляция, дети, йододефицит. 
Огляди літератури, оригінальні дослідження, погляд на проблему, випадок з практики, короткі повідомлення STUDY OF CHANGES IN HEART RATE VARIABILITY IN CHILDREN WITH IODINE DEFICIENCY DURING THE SCHOOL YEAR

๑O. M. Yurchyshyn

\section{HorbachevskyTernopil National Medical University}

SUMMARY. Assessment of the functional state of the cardiovascular system allows to assess the state of adaptation of the child's body and predict the possibility of pathology, including the thyroid gland, at the pre-nosological stage, are relevant and necessary for prevention.

The aim - to study during the school year at the autonomic nervous system functional state primary school children from iodine deficiency.

Material and Methods. Examined 243 children aged 6-10 years. We determined the iodine in urine and heart rate variability.

Results. At the end of the school year, compared to the beginning, children of class 1 secured iodine index decreased adequacy regulation processes by $11 \%(p<0.05)$, relationship stress index in the sample to the index in the background stress test at $38 \%(p<0.05)$. Children in 2 class with iodine deficiency observed increase amplitude of fashion for $21 \%$ $(p<0.05)$, an indicator of the adequacy of regulation processes by $26 \%(p<0.05)$, stress index by $56 \%$ ( $p<0.05)$. In fourthobserved performance index increase tension by $28 \%(p<0.05)$ and reduction of the standard deviation of $37 \%(p<0.05)$. Found that in children with iodine deficiency prevails sympatyc effect autonomic nervous system.

KEY WORDS: heart rate variability; autonomic nervous regulation; children; iodine deficiency. 